\title{
Jorge Amado, crônica e ativismo
}

\author{
Eduardo de Assis Duarte
}

RESUMO: Em Jorge Amado, política e literatura caminham juntas e fazem o romancista conviver intensamente com o homem de imprensa e o militante. Partindo das crônicas publicadas, entre 1942 e 1944, na seção “Hora da Guerra”, do jornal baiano O Imparcial, e reunidas em livro recentemente, o presente trabalho empreende uma reflexão sobre o escritor enquanto cronista e intelectual orgânico - compagnon de route da utopia maior de seu tempo.

PALAVRAS-CHAVE: Jorge Amado; "Hora da Guerra"; crônica e militância

\begin{abstract}
In Jorge Amado, politics and literature go together and make the novelist live intensively as the press man and the militant. Starting from the chronicles published between 1942 and 1944, in the section "Hora da Guerra", the Bahian newspaper O Imparcial, and recently assembled in a book, this present work undertakes a reflection on the writer as an organic columnist and an intellectual compagnon de route of most utopia of his time.
\end{abstract}

KEYWORDS: Jorge Amado; "Hora da Guerra"; chronicle and activism 
Este é tempo de partido,

Tempo de homens partidos.

Carlos Drummond de Andrade,

(1940)

As relações entre jornalismo e literatura no Brasil remontam aos primórdios de nossa produção letrada, sendo praticamente impossível os autores do passado, se maiores ou menores não vem ao caso, ficarem ao largo das redações e se concentrarem na produção livresca. De José de Alencar a Cruz e Sousa, de Machado de Assis a tantos outros do século XIX e, mesmo, do século xx, inúmeros são os casos de escritores com presença constante nas páginas de jornais e revistas. Tanto romances e contos eram publicados primeiro nos periódicos para mais tarde surgirem em livro quanto seus autores atuavam também como cronistas e até repórteres, a exemplo de Machado. Este afirma no "Instinto de Nacionalidade", texto que mais tarde ganharia ares de projeto literário, que o escritor brasileiro devia ser antes de tudo "homem de seu tempo e de seu país", mesmo quando tratasse de assuntos os mais distantes. Esse "sentimento íntimo" ou "instinto de nacionalidade" aponta para o apego à realidade humana, social e política em processo de desenvolvimento histórico e para a figura do homem de letras também como cidadão, testemunha e partícipe do processo.

No caso específico de Jorge Amado, vê-se que a prescrição machadiana nele encontrou ressonâncias profundas, pois foram poucos os escritores do século xx tão fortemente envolvidos com as pulsões históricas de seu tempo e de seu país. O escritor nasce em 1912, pouco antes de ter início o que mais tarde Eric Hobsbawm irá denominar a "era dos extremos". E, já em 1927, vamos encontrá-lo, adolescente ainda, na condição de "foca" da página policial do Diário da Bahia. Dois anos depois, dá-se a aproximação definitiva do escritor com o homem de imprensa: em Salvador, O Jornal publica em folhetins a novela Lenita, escrita em parceria com Édison Carneiro e Dias da Costa, ao mesmo tempo em que mantém o jovem, então com dezessete anos, em sua equipe de reportagem. ${ }^{2}$ Curiosamente, é também na adolescência que Machado de Assis passa da

1. Assis, Machado de. "Notícia da atual literatura brasileira, Instinto de Nacionalidade". In: Obra completa. Rio de Janeiro: Nova Aguilar, 1992, vol. 3, pp. 801-4.

2. TAvares, Paulo. O baiano Jorge Amado e sua obra. Rio de Janeiro: Record, 1980, p. 27. 
tipografia de Paula Brito ao universo do jornalismo fluminense, que só deixaria perto de morrer. E, se temos em Machado o cidadão empenhado em fazer do jornal um veículo de esclarecimento, o mesmo impulso vamos encontrar em Jorge Amado, sempre íntimo das redações e apegado ao fato histórico como motor de sua ficção. E mais: se temos em Machado o afrodescendente que ousa, em pleno apogeu do escravismo, ser sócio oculto da Gazeta de Notícias, jornal "francamente abolicionista", não faltarão, por outro lado, gestos de coragem na trajetória do escritor baiano.

Não foram poucos os órgãos de imprensa a estamparem a assinatura do autor de Jubiabá: em sua terra, além dos citados O Jornal e Diário da Bahia, a revista ETC, o matutino O Imparcial, entre outros; no Rio de Janeiro dos primeiros anos, o Boletim de Ariel, O Jornal, Diário de Notícias, Literatura. Em 1933, recém-chegado à maioridade, já atua como redator-chefe da revista Rio-Magazine. Em 1935, integra a redação de outro periódico, A Manhã, órgão da frente de esquerda ANL - Aliança Nacional Libertadora - empastelado no bojo das agitações políticas daquele ano. Sofre em seguida sua primeira prisão, contrabalançada pela conquista, em 1936, do Prêmio Graça Aranha com o recém-publicado Mar morto.

No ano seguinte, empreende viagem pelos países latino-americanos, período em que dá continuidade à composição de Capitães da areia e encontra tempo para escrever as crônicas mais tarde reunidas por Raúl Antelo no volume Ronda das Américas, e publicadas à época em Dom Casmurro e Diretrizes. ${ }^{4}$ Ao voltar, é preso em Belém do Pará, onde toma conhecimento da fogueira feita com seus livros em Salvador, logo após a decretação do Estado Novo. Em 1939, publica escritos de sua autoria em diversos periódicos da capital, além de assumir, no segundo semestre, a chefia da redação de Dom Casmurro.

Na década seguinte, vamos encontrá-lo novamente nas páginas de Diretrizes, com a edição em folhetim do $A B C$ de Castro Alves, interrompida no terceiro número pela polícia, e da novela Brandão entre o mar e o amor, escrita em conjunto com Graciliano Ramos, Rachel de Queiroz, Aníbal Machado e José Lins. Refugiado nos países do Prata entre 1941 e 1942, Amado faz-se presente em publicações uruguaias e

3. Júnior, Raimundo Magalhães. Machado de Assis desconhecido. 3. ed. Rio de Janeiro: Civilização Brasileira, 1957, p. 143.

4. Amado, Jorge. A ronda das Américas. Estabelecimento do texto, introdução e notas de Raúl Antelo. Salvador: FCJA, 2001. 
argentinas, como La Crítica e Sud. Neste contexto, os anos de 1943 e 1944 como cronista de O Imparcial são apenas um capítulo da longa trajetória do autor pela imprensa, que terá continuidade depois da guerra, em São Paulo, na França, no Rio de Janeiro, em Salvador, isto sem contar as inúmeras tarefas junto às publicações partidárias.

Ser alguém de seu tempo e de seu país conduz Amado ao mundo da palavra impressa tanto quanto às hostes da organização que encarnava a mais generosa utopia da era moderna. E esse duplo movimento intensifica o elo ente o militante e o homem de letras. Em sua ficção, pode-se ler tanto o relato de uma época quanto os meandros do processo histórico que faz as épocas se sucederem. O apego ao real é algo palpável, mesmo quando mesclado à idealização mais romântica, ao recurso mais fantástico ou surrealista. Amado exerce seu talento de rapsodo e enxerta em seus enredos desde histórias captadas aqui e ali a fatos reportados pela imprensa, como em Capitães da areia e Subterrâneos da liberdade. E prossegue no apego documental ao romancear figuras do mundo social e político, num movimento que abarca desde o pai de santo Jubiabá à apaixonada Ofenísia, que sai da crônica mundana de Ilhéus para as páginas de Gabriela, cravo e canela. Ou ainda os muitos coronéis, seres vivos na fala do povo; ou incontáveis personagens inspirados em figuras históricas, como o Juvêncio, de Seara vermelha, que remete a Giocondo Dias; ou Nilo Argolo e Pedro Archanjo, de Tenda dos milagres, que lembram respectivamente Nina Rodrigues e Manoel Querino, protagonistas do debate étnico e racial na Salvador dos começos do século xx.

Seria, pois, de estranhar que esse apego ao tempo e ao país não desembocasse no ímpeto historicista visível em toda a obra, desde a inserção de fatos como a instalação de um governo provisório comunista em Natal, em novembro de 1935, até alusões à revolta de Canudos, presentes em Seara vermelha. Ou ainda, a inclusão da Guerra Civil Espanhola e a menção à recém-nascida Companhia Vale do Rio Doce, transformada ironicamente em "Vale do Rio Salgado", exemplos retirados de Subterrâneos da liberdade. Assim, Jorge Amado, quando não revolve o passado em busca de suas razões históricas, pretende-se narrador do presente e, quiçá, arauto do futuro. Em todos esses movimentos, desponta o servo de Cronos, que não perde de vista o ontem, o agora e o depois, embebido em muitos momentos da certeza messiânica de que à "triste noite fascista" sucederia a "aurora" de um novo tempo, como afirmam os versos de Carlos Drummond de Andrade.

Nesse momento, vale lembrar a conferência de Walter Benjamin "O autor como produtor" proferida em 1934, em Paris, no Instituto para o Estudo do Fascismo, na qual questiona a liberdade de criação dos escritores frente ao contexto de extrema polariza- 
ção política e ideológica então existente. Benjamin declara ser este o tempo em que o artista da palavra terá que decidir "a serviço de quem ele quer colocar a sua atividade". 5 E sacramenta a perda da autonomia do autor ao colocá-lo como "produtor" inserido numa rede discursiva vinculada ao poder e necessariamente em diálogo com os meios de comunicação de massa. Benjamin ressalta sua preocupação com a "função" que a obra irá desempenhar nas "relações de produção literária"6 de seu tempo (p. 189) e demonstra sua assertiva ressaltando o papel político dos escritores na União Soviética:

\begin{abstract}
Eu gostaria de chamar a atenção para Sergei Tretiakov e para o tipo de "escritor operante" que ele definiu e encarnou. Este escritor operante configura o exemplo mais tangível para a dependência funcional em que sempre e em todas as circunstâncias estão a correta tendência política e a técnica literária progressista. [...] Tretiakov distingue o escritor operante do escritor informativo. A sua missão não é noticiar, mas lutar; não é desempenhar o papel de espectador, mas de intervir ativamente. ${ }^{7}$
\end{abstract}

Benjamin prossegue chamando atenção para a "reformulação das formas literárias", que exemplifica com o Teatro Épico de Brecht, e destaca o papel da imprensa pela possibilidade revolucionária de superar não apenas velhas distinções entre os gêneros, "entre escritor e poeta, entre pesquisador e divulgador", mas a própria "distinção entre autor e leitor". Ao encarar a mídia como "aparelho de produção", o filósofo recorre a Brecht para conclamar os intelectuais progressistas a não se limitarem a "alimentá-lo", mas, na medida do possível, "alterá-lo no sentido do socialismo". ${ }^{8}$ Este é, pois, o tempo de Jorge Amado. Mas seu país não é a União Soviética.

O compromisso com o engajamento faz o escritor trocar o exílio no Prata pelo Brasil do Estado Novo, assim que o país declara guerra ao Eixo Alemanha-ItáliaJapão. Amado se entrega à polícia em Porto Alegre e passa a viver em Salvador nos dois anos seguintes, em regime de liberdade vigiada, não sem antes passar pelo presídio da Ilha Grande, no Rio de Janeiro. É o momento em que vêm a público Terras do sem-fim e São Jorge dos Ilhéus, e também do retorno à atividade jornalística no

5. Benjamin, Walter. Sociologia. Organização de Flávio R. Kothe. São Paulo: Ática, 1985, p. 188.

6. Id., p. 189.

7. Id., p. 190.

8. Id., p. 194. 
Brasil, através da coluna "Hora da Guerra", publicada por quase dois anos a partir de dezembro de 1942, no periódico baiano O Imparcial, órgão de oposição ao governo Vargas. Ao reentrar no ambiente da redação, o autor retoma em verdade um espaço que nunca deixou de ocupar.

A crônica "A poesia também é uma arma”, publicada no último dia daquele ano, dá bem a medida do envolvimento do escritor no front ideológico então vivido pelos intelectuais progressistas:

Numa manhã de luto para a inteligência, os nazifascistas italianos e alemães, que usavam a máscara nacionalista de Franco, encostaram num muro de fuzilamento o poeta Federico García Lorca, cantor dos gitanos, da Andaluzia, da beleza de Espanha. Era a voz mais popular e o coração mais ardente que nascera em Granada, e em Granada, a cidade que ele amava sobre todas, os inimigos da Cultura e da Inteligência o fuzilaram. ${ }^{9}$

A menção a Lorca já nas primeiras linhas confere à crônica o tom extremado próprio à ausência de neutralidade frente aos campos que então se digladiavam, e esta será a marca registrada da seção em todo o período em que é publicada. ${ }^{10}$ Cronista armado, o autor traz à tona o conflito espanhol que precede a grande guerra e, com isto, objetiva tanto equiparar os falangistas seguidores de Franco aos fascistas e nazistas, que tinha como alvo maior, quanto tomar Lorca como símbolo da Inteligência e da Cultura perseguidas por seu engajamento. O poeta foi executado em 1936, sem ter culpa ou condenação formalizadas judicialmente, mas, segundo consta, por ser "mais perigoso com a caneta do que outros com o revólver", palavras atribuídas a um de seus algozes, e que se encaixam à perfeição no título escolhido por Amado: "A poesia também é uma arma".

A crônica enumera em seguida nomes ilustres expulsos de seus países ou assassinados como Lorca. E cita Freud, os irmãos Thomas e Heinrich Mann, Stefan Zweig, que se suicida no Brasil, o espanhol Antonio Machado, morto num campo de concentração, entre outros. Amado alude ao chamamento pela "unidade dos escritores" contra

9. Amado, Jorge. Hora da Guerra. Seleção de Myriam Fraga e Ilana Seltzer Goldstein. Prefácio de Boris Fausto. São Paulo: Companhia das Letras, 2008, p. 31.

10. Em seu prefácio ao volume, o historiador Boris Fausto já de início destaca o maniqueísmo expresso nas assertivas do cronista, que o faz encampar e expressar a "cesura" entre as "forças do bem" e as "forças do mal" (Id., pp. 14-5). 
a "escravidão nazista", proposta que ganhava no Brasil o apoio de nomes tão díspares em suas posições políticas e estéticas quanto os de Graciliano Ramos e Augusto Frederico Schmidt. Para ele, era o momento de congregar tanto os adeptos da "arte social" quanto os da "arte pela arte" numa "Legião da Cultura pela Vitória”. O engajamento é explícito e vem acompanhado de indagações como esta: "Por que alguns [artistas, escritores, sábios e poetas] se deixam ficar, cômoda e criminosamente, perdidos em sonetos e em poemas, em inoportunas discussões de ordem estética?"."

Como se vê, é um tempo "áspero", como o próprio autor define em um de seus títulos. Tempo em que o engajamento traz consigo a certeza militante e faz com que o texto de Amado venha refutar aquela outra lição machadiana sobre a crônica ser o "consórcio do útil com o fútil, do sério com o frívolo"... ${ }^{12} \mathrm{Na}$ "Hora da Guerra", o que vamos ter é a união do útil com o que, segundo o ponto de vista do militante esquerdista, seria o justo. E o autor conclui seu chamamento de 31 de dezembro de arma em punho. Em vez de desejar boas passagens ou feliz ano-novo, vocifera: "Em nome do Brasil e em nome da cultura estamos nós, os escritores e artistas, em guerra contra o nipo-nazifascismo. Vamos provar que nossas armas sabem também ferir e matar". ${ }^{13} \mathrm{O}$ tom beligerante prossegue e adentra os escritos jornalísticos de 1943 e 1944, ao contrário do que ocorre em Terras do sem-fim, romance elogiado por Antonio Candido justamente por evitar a simplificação que colocaria todos os coronéis como vilões e todos os camponeses como heróis. Na crônica de 15 de janeiro de 1943, em que aborda a festa do Senhor do Bonfim, em Salvador, Amado transforma o santo nada menos que em "padroeiro das Nações Unidas". E não perde a chance de equiparar o nazismo à escravidão, atualizando o mote que estará presente em várias crônicas da série, em função dos pressupostos racistas que comandaram a política e o belicismo alemães naquele tempo. Amado vai além do escritor "informativo" para ser também escritor "operante", nos termos de Tretiakov: além da descrição jornalística do ritual do Bonfim — em que noticia a politização do evento com a colocação na igreja da "vela da vitória" -, tira partido da notícia para fazer proselitismo e afirmar aos leitores que, sob o nazismo, “jamais a procissão e a lavagem da igreja se realizariam". ${ }^{14}$

\footnotetext{
11. Id., p. 32.

12. Assis, Machado de. Op. cit., p. 959.

13. Id., p. 33.

14. Id., p. 36 .
} 
Num texto antológico em que discute o estatuto da crônica, Carlos Heitor Cony a contrapõe ao discurso jornalístico por escapar da propalada objetividade na transcrição dos fatos exigida ao homem de imprensa, seja ele repórter ou editor. Apesar de situá-la quase como antijornalismo, exalta o gênero destacando o necessário contingente de emoção agregado como contrapeso à frieza e ao distanciamento exigidos de quem produz informação.

Banida do texto jornalístico, a emoção foi considerada cafona, desnecessária, primária. Nelson Rodrigues reclamava da falta de pontos de exclamação nas manchetes, mesmo nas mais prosaicas. Exemplo: "Pânico na Bolsa de Nova York!" é uma coisa. Sem exclamação é outra. Não se conclua que a emoção seja simples pontuação. Ela é uma forma de ver o mundo, um estilo de sofrer ou de gozar a vida. ${ }^{15}$

Cony ressalta a importância do desnudamento da intimidade no jornal como forma de humanização do autor e consequente identificação com o público. Pois em Hora da Guerra é possível detectar o quanto a subjetividade - e as emoções - do autor se mesclam à retórica e aos propósitos do intelectual engajado. Na crônica de 19 de janeiro de 1943, intitulada sintomaticamente "Ódio", Amado apela à emoção e assim se dirige às leitoras:

Que outro sentimento pode guardar um coração, mesmo que seja o teu doce coração de mulher, em relação aos assassinos nazis, senão o de um profundo e duradouro ódio? Um dia, nos dias de paz e de idílio, tu aprendeste que só o amor constrói na face do mundo. [...] Ah!, te direi hoje outra verdade nesta hora de guerra: quando os assassinos se soltarem sobre o mundo, em relação a eles só o ódio é construtivo. ${ }^{16}$

Após esse introito dirigido à leitora, denuncia os massacres alemães em cidades do Leste Europeu, com destaque para o extermínio em massa, a deportação e o aprisionamento em campos de concentração. E ao final arremata: "Que o ódio encha teu coração. [...] Ódio, amiga, ódio e mais ódio aos assassinos, ódio até que o último seja exterminado, e

15. Cony, Carlos Heitor. "A crônica como gênero e como antijornalismo". Folha de S.Paulo, Caderno Ilustrada, 16 out. 1998.

16. Id., p. 40 . 
até que a lembrança de sua nefanda memória haja desaparecido!" ${ }^{17}$ A retórica amadiana transforma o ódio em leit motif e isto se repete noutros textos da coluna. A vingança é outro sentimento explorado, a ponto de defender a absolvição de um cidadão cearense preso por assassinar um italiano residente em Fortaleza, como vingança pelo afundamento de um navio brasileiro por submarino italiano.

Os ataques a navios brasileiros serão abordados em diversas inserções. No texto de 2 de fevereiro de 1943, o cronista se faz ficcionista e, como Machado, cria um personagem narrador, no caso um sobrevivente de um ataque marítimo que escreve a "Carta do marinheiro a Iemanjá". E, novamente, o apelo sentimental conduz a argumentação:

Dona Janaína...

Nesta tua festa do Rio Vermelho eu nada te trago senão a lembrança do meu navio. [...] Íamos pacificamente $[. .$.$] conduzindo mercadorias e passageiros de um porto para outro.$ E as feras chegaram, nos seus navios assassinos, e do meu barco, Iemanjá, resta apenas a lembrança dos que morreram e foram muitos! ${ }^{18}$

Ao final, pode-se ler:

Só te trago uma lembrança, como presente, só te peço também uma coisa: vingança. Teus filhos, Inaê, estão prontos para a luta. Os assassinos morrerão, um por um. ${ }^{19}$

Será, pois, nessa condição de absoluta e, até mesmo, enfurecida parcialidade que o escritor, então com trinta anos, irá desempenhar seu papel de cronista desse tempo de homens partidos..$^{20}$ Amado trata sobretudo da guerra e de suas consequências, sem

17. Id., p. 42.

18. Id., p. 49.

19. Id., p. 51.

20. Nessa linha, o crítico Benedito Veiga aponta a omissão amadiana quanto à "cumplicidade da União Soviética com a Alemanha, em parceria só desfeita posteriormente", e se refere ainda ao "massacre de Katyn", onde foram mortos " 22 mil poloneses, sendo 15 mil prisioneiros de guerra e o restante pertencente à elite intelectual, cultural e religiosa polonesa”. Veiga cita Vasquez, estudioso do episódio, que se vale de documentos da época só posteriormente revelados, para apontar o governo soviético como responsável pelo extermínio, levado a cabo pela NKVD, a temida polícia secreta dos tempos de Stálin. 
nunca perder a chance de espezinhar os integralistas de Plínio Salgado e demais simpatizantes do Eixo, tratando-os sempre na condição de "quinta coluna", ou seja, de brasileiros traidores por apoiarem o nazifascismo. E será com a mira apontada para estes que escreve a coluna de 27 de fevereiro de 1943, intitulada sintomaticamente "Hitler contra Zumbi dos Palmares".

Nesse texto, o autor discorre sobre as bases racistas do III Reich e se vale da paráfrase e da citação - também utilizadas por Machado de Assis, sobretudo em temas mais espinhosos - para, apoiando-se em afirmativas alheias, tecer suas considerações sobre o racismo como política de governo e forma de dominação nazista. Observemos primeiramente a estratégia machadiana: no início de 1871, antes ainda dos debates que redundaram na aprovação da Lei do Ventre Livre, Machado publica incisiva crônica no periódico Semana Ilustrada, em que comenta notícia envolvendo senhoras que obrigavam suas escravas à prostituição. $\mathrm{O}$ autor clama em favor da "fraqueza e miséria ofendidas pela especulação" e, embora não use termos como "cafetina" ou "cafetinagem", pede a "punição pública dos traficantes". Mas, não sem antes se proteger, indicando a autoridade responsável pela apuração dos delitos, além de se valer da menção aos artigos de outro cronista - Peçanha Póvoa - , a quem louva por ter levantado a questão na imprensa. Dado o "clima opressivo" então vigente (Magalhães Júnior) e a natureza explosiva do tópico, o escritor caramujo encontra ainda outras formas de disfarce e se oculta por trás do pseudônimo de "Dr. Semana". ${ }^{21}$

Em "Hitler contra Zumbi dos Palmares", Jorge Amado, embora dispense o disfarce da autoria, retoma o procedimento e respalda seu discurso pela palavra abalizada de um especialista. Inicia mencionando Artur Ramos, "sábio que dedicou sua vida aos estudos sobre o negro brasileiro", que, por sua vez, publicara artigo em que citava matéria do jornal The Nation assinada por Hans Habe e intitulada "The Nazi Plan for Negroes". Em seguida, inclui-se entre os afrodescendentes: "digo nós, num caráter geral, porque os planos de Hitler são de referência a todos os negros, mulatos e mestiços, e

Veiga, Benedito. “Jorge Amado e os judeus perseguidos na Segunda Guerra Mundial”. In: Fraga, M.; Fonseca, A.; HoIsel, E. (Orgs.). Jorge Amado: Cacau: a volta ao mundo em oitenta anos. Salvador: Casa de Palavras, 2014, pp. 214-5.

21. Assis, Machado de, apud Júnior, R. Magalhães. Op. cit., p. 161; ver também: DuARTe, Eduardo de Assis (Org.). Machado de Assis afrodescendente: escritos de caramujo. 2. ed. Rio de Janeiro: Pallas; Belo Horizonte: Crisálida, 2007, pp. 30-1. 
ele sempre considerou o Brasil 'um miserável país de mestiços' que devia ser civilizado pelos 'cultos arianos nazistas'”. ${ }^{22}$

Menciona logo adiante as teses do "imbecil Congresso de Nuremberg", que estabeleceram a premissa pela qual só se considerava cidadão alemão quem tivesse os quatro avós alemães. Na crônica em que lembra o assassinato de García Lorca, Amado já havia se referido ao exílio de Thomas Mann, excluído da cidadania germânica por ser filho de uma brasileira... E contrapõe a mestiçagem existente no Brasil como prova de nossa "democrática isenção do preconceito de raça", para citar em seguida exemplos de afro-brasileiros ilustres, de Henrique Dias a Tobias Barreto, de Zumbi dos Palmares a Machado de Assis.

$\mathrm{Na}$ sequência, a crônica atinge seu clímax quando Amado enumera os seis itens do plano nazista para os negros, do qual cumpre destacar o mais escabroso:

$3^{\circ}$ ) É inteiramente proibido o casamento de negros, mulatos e mestiços com brancas ou vice-versa. As relações sexuais entre membros das duas raças (arianos e não arianos) estão sujeitas a pena de morte..$^{23}$

Para, em seguida acrescentar:

Estes seis itens iriam reger a vida dos negros, mulatos e mestiços se Hitler dominasse o mundo. Seriam estes itens que iriam reger a vida dos brasileiros, a quem Hitler considera 'miseráveis mestiços inferiores' (vide edição completa de Minha luta. A traduzida no Brasil suprimiu o trecho), se Plínio Salgado e a quinta-coluna tivessem realizado a planejada entrega do Brasil. ${ }^{24}$

Como se vê, além de trabalharem pelo alinhamento brasileiro ao Eixo Alemanha-ItáliaJapão, seus simpatizantes locais estariam também envolvidos numa fraude ideológica de proporções nada desprezíveis ao retirarem da bíblia nazista a menção à população miscigenada e multiétnica que dá forma ao nosso povo. E o fato de os integralistas

\footnotetext{
22. Id., p. 63.

23. Id., p. 65.

24. Ibid.
} 
contarem em suas fileiras com a presença de inúmeros afro-brasileiros, alguns deles ilustres, só torna a questão ainda mais espinhosa.

A acusação é gravíssima e se projeta rumo ao futuro. Conferimos a afirmativa cotejando edições mais recentes (infelizmente não tivemos acesso ainda à primeira edição brasileira, publicada em 1934), tanto em português, quanto em outros idiomas, e não encontramos a frase citada pelo cronista. Dada a dificuldade de acesso ao original de 1925, solicitamos a ajuda de colegas alemães, sendo prontamente atendidos por Marcel Vejmelka, professor da Universidade de Mainz e estudioso de Jorge Amado. Vejmelka pesquisou a edição de Mein Kampf publicada em 1943 pela Eher Verlag, editora oficial do partido nacional-socialista, onde se lê ser reprodução na íntegra do original. E lá também não foi localizada a menção aos "miseráveis mestiços" brasileiros. No entanto, no capítulo "Povo e raça", após mencionar que a Natureza não prescreve a associação dos mais fracos com os mais fortes, e que a fusão de uma "raça superior" com uma "inferior" seria um "golpe quase mortal" contra a Natureza e o "trabalho de aperfeiçoamento executado através de centenas de milênios”, o chefe nazista faz menção explícita à América do Sul:

A experiência apresenta inúmeras provas disso. Mostra com claridade assustadora que, em cada caso de mistura do sangue do ariano com povos inferiores, o resultado foi o fim do portador de cultura. A América do Norte, cuja população consiste na maior parte de elementos germânicos que somente muito pouco se misturaram com povos inferiores e de cor, mostra outra humanidade e cultura que a América Central e do Sul, onde os imigrantes, na maioria latinos, se misturaram às vezes em grande escala com os autóctones. Já por este exemplo se poderá perceber de forma clara e nítida os efeitos da mistura racial. O germano do continente americano, que se manteve racialmente puro e não misturado, ascendeu a ser senhor desse continente; permanecerá senhor enquanto não se tornar vítima do sacrilégio da mistura do sangue. ${ }^{25}$

25. "Die geschichtliche Erfahrung bietet hierfür zahllose Belege. Sie zeigt in erschreckender Deutlichkeit, daß bei jeder Blutsvermengung des Ariers mit niedrigeren Völkern als Ergebnis das Ende des Kulturträgers herauskam. Nordamerika, dessen Bevölkerung zum weitaus größten Teile aus germanischen Elementen besteht, die sich nur sehr wenig mit niedrigeren farbigen Völkern vermischten, zeigt eine andere Menschheit und Kultur als Zentral - und Südamerika, in dem die hauptsächlich romanischen Einwanderer sich in manchmal großem Umfange mit den Ureinwohnern vermengt hatten. An diesem einen Beispiele schon vermag man die Wirkung der Rassenvermischung klar und deutlich zu er-kennen. Der rassisch rein und 
Na passagem, o Brasil e os brasileiros aparecem indiretamente, no bojo da comparação com a riqueza estadunidense, colocada como fruto de uma presença ariana não miscigenada. E a propalada ofensa - "miseráveis mestiços inferiores" -, apesar de não explicitada, pode ser perfeitamente deduzida, sobretudo se o leitor percorre os demais capítulos, em que se percebem os fundamentos preconceituosos do arianismo e da eugenia, propagados como passaportes para o futuro e transformados durante a guerra em brutal "limpeza étnica". Por outro lado, cumpre fazer justiça e lembrar que o parágrafo acima está presente na íntegra na tradução de Klaus Von Puschen, publicada em São Paulo em 2001. ${ }^{26}$

A menção explícita à inferioridade congênita dos brasileiros é encontrada em outro escrito, mais precisamente do Conde de Gobineau, um dos formuladores do racismo "científico" do século xix e, certamente, fonte de consulta do autor de Mein Kampf. Com efeito, Arthur de Gobineau, depois de passar alguns meses no Rio de Janeiro e ser diversas vezes recebido em palácio por d. Pedro II, não esconde seu desprezo pelo perfil étnico que encontrava nas ruas da Corte: "povo infame: todos mulatos, a ralé do gênero humano e costumes condizentes". ${ }^{27}$

Voltando a Amado e à sua acusação, vale indagar: teria a censura de nossos integralistas se perpetuado e impregnado traduções e edições futuras? Ou, por outro lado, teria o ímpeto do ficcionista preponderado sobre o apego aos fatos exigido do homem de imprensa? A verdade é que os fatos falam por si e o Holocausto, mais do que

unvermischt gebliebene Germane des amerikanischen Kontinents ist zum Herrn des-selben aufgestiegen; er wird der Herr so lange bleiben, so lange nicht auch er der Blutschande zum Opfer fällt." (Mein Kampf, S. 313-4, Kap, 11 "Volk und Rasse", Zwei Bände in einem Band. Ungekürzte Ausgabe. Zentralverlag der NSDAP., Frz. Eher Nachf., G.m.b.H., München, 851-5. Auflage 1943 [Band I 1925, Band II 1927]. Tradução de Marcel Vejmelka).

26. Hitler, Adolf. Minha luta. Tradução de Klaus Von Puschen. São Paulo: Centauro, 2001.

27. Gobineau, Arthur, apud Raeders, Georges. O conde de Gobineau no Brasil. Trad. Rosa Freire de Aguiar. Rio de Janeiro: Paz e Terra, 1996, p. 77. O autor de A origem da desigualdade entre as raças retoma seu ponto de vista em artigo publicado em Paris em 1873: "a grande maioria da população brasileira é mestiça e resulta de mesclagens contraídas entre os índios, os negros e um pequeno número de portugueses. Todos os países da América, seja do norte ou do sul, hoje mostram, incontestavelmente, que os mulatos de distintos matizes não se reproduzem além de um número limitado de gerações. A esterilidade nem sempre existe nos casamentos; mas os produtos da raça gradualmente chegam a ser tão malsãos e inviáveis que desaparecem antes de dar a luz, ou deixam rebentos que não sobrevivem." (Apud RAEDERS, 1996, p. 85). 
todos eles, comprova o ódio nazista às "raças inferiores". Concluindo, pode-se dizer que Amado transita entre o escritor "informativo" e o "operante", definidos por Tretiakov. E isto em toda a sua vida de romancista brasileiro mais lido e festejado pelos leitores. Em que medida se apropria de seu tempo e de seu país como régua e compasso para a escrita é algo que nos desafia. Lembro então o José de Alencar de Ao correr da pena, para quem o cronista, quando inventa em vez de contar, excede os limites da crônica. ${ }^{28}$ Seria este o caso? Com a palavra os leitores e estudiosos de Jorge Amado.

Eduardo de Assis Duarte é professor voluntário no programa de pós-graduação em letras da Universidade Federal de Minas Gerais e autor de Jorge Amado: romance em tempo de utopia (ed. Record).

28. ALENCAR, José de. "Ao Correr da Pena”. Correio Mercantil, Rio de Janeiro, 24 set. 1854. 